

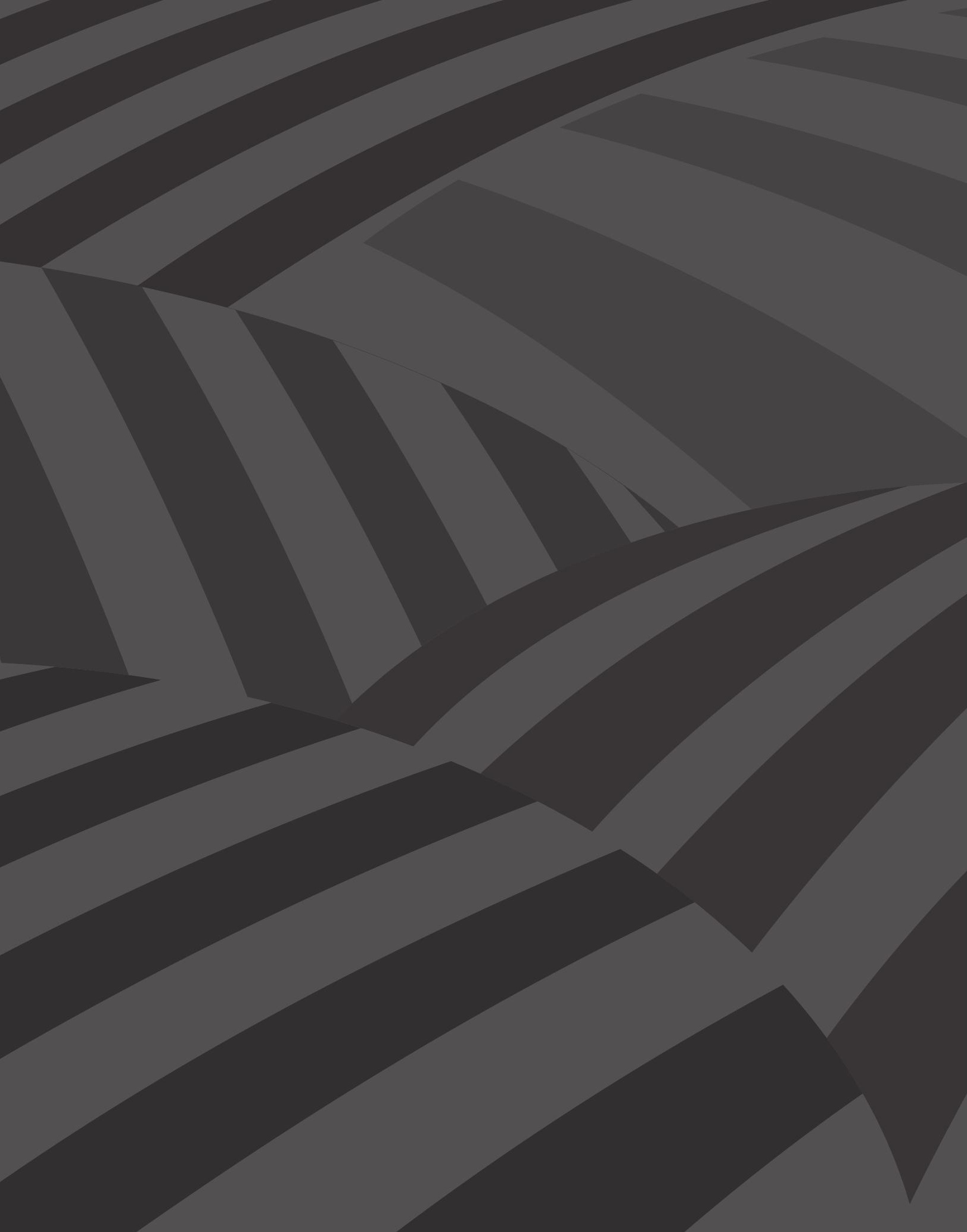




\section{Ordenamiento territorial interétnico para la construcción de paz en el Catatumbo, Norte de Santander (Colombia)}

Por Juliana Duarte Ospina*

Resumen: Este artículo aborda el conflicto territorial entre el pueblo indígena Barí y la Asociación Campesina del Catatumbo (ASCAMCAT), que se expresa en el traslape de la pretensión para ampliar los dos resguardos indígenas del pueblo Barí y la constitución de la Zona de Reserva Campesina del Catatumbo, en los municipios de Tibú, El Tarra, Teorama, Convención y El Carmen, en Norte de Santander. El análisis se enmarca en el posconflicto y en la implementación del Acuerdo de Paz y sus programas, especialmente los propuestos en la Reforma Rural Integral y en el punto sobre la Solución al problema de las drogas ilícitas. A su vez, este artículo presenta el conflicto territorial entre indígenas y algunas comunidades campesinas, el cual fue visibilizado en esta coyuntura del posconflicto, y que se ha expresado en el desarrollo de la Sentencia T-052 de 2017 de la Corte Constitucional. Es en este contexto donde emergen con más fuerza propuestas de ordenamiento y de diálogo interétnico para la elaboración de propuestas sobre el territorio, teniendo en cuenta este elemento como eje fundamental de las transformaciones desde las comunidades y la construcción de paz.

Palabras claves: conflictos territoriales, interétnico, pueblo Barí, organizaciones campesinas, Catatumbo, construcción de paz.

\section{Inter-ethnic Territorial Planning for the Peacebuilding at Catatumbo, Norte de Santander (Colombia)}

Abstract: This article develops an analysis of the territorial conflict between the indigenous Barí and the peasant organization ASCAMCAT in Catatumbo, North of Santander. This conflict is expressed in the overlapping of the indigenous claim and the constitution of the Catatumbo Peasant Reserve Zone in Tibú, El Tarra, Teorama, Convención and El Carmen. The analysis frames in the post-conflict and the implementation of the Peace Agreement and its programs, especially those proposed in the Integral Rural Reform and on the Solution to the problem of illicit drug. This article presents the territorial conflict between indigenous and some peasant communities, which

* Socióloga y magíster en Geografía de la Universidad Nacional de Colombia. Investigadora de la línea Movimientos Sociales, Interculturalidad y Construcción de Paz, del Instituto de Estudios Interculturales de la Pontifica Universidad Javeriana de Cali. Correo electrónico: juduarteos@gmail.com 
was evident a few years ago. And has been expressed in the development of Judgment T-052 of 2017 of the Constitutional Court. It is in this context that proposals for planning and inter-ethnic dialogue for building proposals for territory, taking into account this element as the fundamental axis of the transformations from the communities and peacebuilding.

Keywords: territorial conflicts, inter-ethnic, Barí indigenous, peasant organizations, Catatumbo, peacebuilding.

Cómo citar este artículo: Duarte Ospina, Juliana (2020). Ordenamiento territorial interétnico para la construcción de paz en el Catatumbo, Norte de Santander (Colombia). Revista Controversia, 214, 91-122.

Fecha de recepción: 1 de octubre de 2019

Fecha de aprobación: 16 de diciembre de 2019

\section{Introducción}

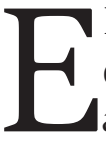

1 proceso de paz y la firma del Acuerdo Final para la Terminación del Conflicto y la Construcción de una Paz Estable y Duradera (en adelante Acuerdo de Paz), generaron nuevas configuraciones en las regiones donde por años ha persistido el conflicto armado, así como la emergencia de otros actores y la agudización de conflictividades que existían de larga data en estos lugares. Para la región del Catatumbo tanto el proceso de paz como la firma del Acuerdo de Paz originaron expectativas en las comunidades campesinas e indígenas frente a nuevas oportunidades para la ruralidad y la construcción de paz. Igualmente, las conflictividades existentes en el territorio, asociadas al acceso a tierras y garantía de derechos fundamentales, evidenciaron la necesidad de la implementación del Acuerdo de Paz en los diferentes puntos, así como propiciar espacios para la construcción de paz desde diferentes perspectivas integrando la diversidad de actores que están presentes en la región.

A continuación se presentan algunas reflexiones sobre cómo la firma del Acuerdo de Paz y el posconflicto configuraron una serie de espacios para el diálogo, la visibilización de desigualdades que ya estaban pre- 
sentes en las regiones más afectadas por el conflicto armado y la posibilidad de propuestas a partir de la participación y construcción colectiva. Para ello, es importante definir qué se entiende por posconflicto en el marco del análisis a desarrollar:

A partir de los documentos orientadores producidos por la Organización de las Naciones Unidas (ONU), el término posconflicto se asocia con una etapa de estabilización política en la cual se prioriza un proceso de construcción de paz en el cual se busca contener los efectos directos de la guerra y mejorar la gobernabilidad del Estado y sus instituciones. Ello puede incluir, como medidas de contención de la violencia: el desarme de los actores armados, la destrucción de armas, la asistencia al retorno de los refugiados y desplazados; y como medidas de sostenimiento de la paz: el apoyo y monitoreo de los procesos electorales, la protección efectiva de los derechos humanos y el fortalecimiento de la democracia. (Ulloa y Coronado, 2016, p. 32).

Teniendo en cuenta lo anterior, los procesos que se describen a continuación no se abordan desde la perspectiva del posacuerdo, pues no solo se remiten al periodo posterior a la firma del Acuerdo de Paz, sino a procesos y conflictos de vieja data que se han evidenciado con mayor fuerza en los últimos años y para los cuales este no supone su superación. Como lo señalan Ulloa y Coronado (2016, p. 32), el posconflicto también incluye medidas apropiadas para la construcción de paz, como el tratamiento de disputas por la tierra y el territorio, y su resolución, como se propone en el Punto 1 con el mecanismo de conflictos territoriales.

En este contexto se exponen algunas propuestas territoriales de comunidades indígenas y campesinas del Catatumbo que emergieron con más fuerza luego de la firma del Acuerdo de Paz y en el marco del posconflicto, que a su vez han contribuido a generar otros escenarios de diálogo y reconciliación a partir de la convergencia de discusiones alrededor de la defensa del territorio, así como puntos de conflicto y de encuentro que han conllevado la formulación de propuestas para la construcción de paz desde lo local, teniendo en cuenta que el enfoque 
territorial planteado en el Acuerdo de Paz propone reconocer la diversidad, las relaciones de poder locales y las condiciones en las cuales se desarrollan los conflictos y las necesidades de las comunidades.

Así, para comprender la complejidad del conflicto es importante entender el territorio como "el producto de las relaciones de poder expresadas como territorialidades que pretenden imprimirse en el terreno” (Zaragocin, 2018, p. 14). Por su parte, Patricia Sánchez afirma que el territorio articula el concepto de espacio geográfico con la necesidad de apropiación que tienen los diferentes actores en el marco del capitalismo y concluye:

El territorio no es solo un escenario en el que los sujetos individuales o colectivos desarrollan acciones, sino una condición para su propia existencia como sujetos. No es un espacio solamente físico, sino social, político y cultural que define la propia existencia del sujeto que se lo apropia. (2016, p. 111).

En ese sentido, el territorio se refiere a un espacio político, donde cada actor tiene agencia, capacidad de movilización y de transformación. Para el pueblo Barí el territorio o ishtana es la vida misma y su existencia, donde viven sus ancestros y es, en sí mismo, su forma de pervivencia física y cultural. Mientras para las comunidades campesinas agrupadas en la Asociación Campesina del Catatumbo (ASCAMCAT), el territorio es el lugar donde ellos pueden desarrollar sus actividades propias como la economía campesina y, en ese mismo sentido, mantener su relación con la tierra. Sobre esto Guevara Agudelo menciona:

Los pueblos indígenas buscan principalmente el reconocimiento de sus derechos territoriales dada la especial relación que tienen con el territorio y como ejercicio de re-existencia, lo cual sucede con el reconocimiento de una propiedad colectiva sobre su territorio usurpado. Del otro lado, tenemos a las comunidades campesinas que buscan el ejercicio autónomo de sus costumbres, formas de economía solidaria y de su especial forma de comprender la agronomía, en lo que la distribución de tierras les permitirá su desarrollo como sujetos políticos. (2017, p. 126). 
Retomando lo planteado por Zaragocin (2018), el análisis del posconflicto brinda elementos para llevar a cabo una práctica geográfica crítica, evidenciando las propuestas de ordenamiento territorial y construcción del territorio desde las comunidades como actores con agencia y capacidad de transformación. Se hace mención de algunos de los mecanismos y programas a implementar en la región, debido a que es importante tenerlos en cuenta para el análisis de los conflictos actuales.

Así mismo se describen algunos de los programas desarrollados en el marco de la Reforma Rural Integral ${ }^{1}$ en el Catatumbo, así como las propuestas de ordenamiento y los conflictos territoriales que emergen con más fuerza en el marco del posconflicto, siendo el territorio un espacio donde se proponen alternativas al desarrollo capitalista asociados con la infraestructura o propuestas relacionadas con agronegocios o economías extractivas. Además, el territorio se constituye en un eje fundamental para comprender las transformaciones estructurales que se proponen en el Acuerdo de Paz y en las propuestas de las comunidades, expresadas materialmente en la constitución de resguardos indígenas y la formalización de las Zonas de Reserva Campesina (ZRC).

Este análisis se propone en el marco del posconflicto y luego de la firma del Acuerdo de Paz, debido a que se pueden retomar algunos efectos de este proceso y algunas discusiones que tomaron fuerza luego de este suceso, y que están relacionadas con la sustitución de cultivos de uso ilícito; el ordenamiento socio-territorial; la necesidad de generar economías locales alternativas para las comunidades, que eviten el desarrollo de las economías ilegales de frontera que propendan para agudizar los escenarios de violencia y la presencia de actores armados ilegales con intereses allí; y la defensa del ambiente.

1 Según el informe del Instituto Kroc: “crea una serie de instrumentos y mecanismos para lograr la democratización del acceso a la tierra en Colombia, regularizar y brindar seguridad jurídica sobre los derechos de propiedad de la tierra y promover una distribución equitativa de la misma” (2018, p. 27). 
En primer lugar, se hace una breve descripción de la región del Catatumbo, donde se exponen sus aspectos geográficos y algunos elementos para comprender la territorialidad de las poblaciones campesinas y especialmente del pueblo Barí. Posteriormente se presentan las implicaciones del Acuerdo de Paz en la región y algunos de los mecanismos implementados en el territorio relacionados con el punto 1: Hacia un nuevo campo colombiano: Reforma Rural Integral. Luego se describe el conflicto territorial entre comunidades campesinas e indígenas debido a sus pretensiones territoriales, el cual se ha expresado especialmente en la Sentencia T-052 de 2017 de la Corte Constitucional, para pasar a algunas propuestas planteadas por las partes. Finalmente se plantean algunas reflexiones y conclusiones respecto a las propuestas sobre el territorio y la construcción de paz en el Catatumbo.

\section{La región del Catatumbo}

Está ubicada en la parte norte del departamento de Norte de Santander, al nororiente del país. Es frontera con Venezuela y se compone de ocho municipios: Tibú, Sardinata, San Calixto, Hacarí, El Tarra, Convención, Teorama y El Carmen. Su geografía es diversa, compuesta por valles, ríos, montañas, zonas frías y calientes, incluso selvas que no han sido exploradas al norte de la región, en territorio indígena. Esta misma diversidad ha generado que el Catatumbo esté en la mira de varios intereses económicos, como la ganadería, el petróleo, el carbón y algunas economías ilegales ${ }^{2}$, y haya sido una de las regiones más afectadas por el conflicto social y armado del país, debido a la presencia de grupos armados legales e ilegales atraídos tanto por el desarrollo de economías extractivas y actividades ilegales, como por su ubicación de frontera.

2 Cuando mencionamos economías ilegales no solo se hace referencia al cultivo de hoja de coca y parte de su procesamiento, también se señala el tráfico ilegal de gasolina gracias a la presencia de parte del tramo del oleoducto de Caño-Limón Coveñas. También contrabando de varios bienes y espacies, entre otras. 
De acuerdo con el Centro Nacional de Memoria Histórica (CNMH), el Catatumbo se ha caracterizado por su gran potencial agrícola e hídrico, lo que ha contribuido a la organización de varias cooperativas y escenarios de economía campesina y tiene una tradición organizativa importante, como lo refleja el informe Catatumbo memorias de vida $y$ dignidad (2018). Actualmente las organizaciones campesinas que se encuentran allí son la ASCAMCAT, el Comité de Integración Social del Catatumbo (CISCA), el Movimiento por la Constituyente Popular (MCP), las Juntas de Acción Comunal y otros movimientos sociales que han emergido recientemente, como el Movimiento Comunal del Catatumbo con origen en Versalles (Tibú) y la Asociación por la Unidad Campesina del Catatumbo (Asuncat) creada en el 2019.

Las comunidades indígenas del pueblo Barí están organizadas en dos resguardos: Motilón Barí y Catalaura, que comprenden los municipios de Tibú, El Tarra, Teorama, Convención y El Carmen, que son a su vez los lugares donde se presentan los conflictos con comunidades campesinas. Actualmente el pueblo Barí habita la zona norte de la cuenca del río Catatumbo, conformada por las subcuencas del río de Oro (Ikiboki), el río Intermedio (Antrayboki), El Tarra (Daatriba) y los caños San Miguel, El Martillo y El Brandy, estos últimos en el municipio de Tibú. Su zona de poblamiento ancestral correspondía a la totalidad de la cuenca del río Catatumbo, ${ }^{3}$ desde el páramo Jurisdicciones y la serranía de los Motilones, bajando hasta el lago de Maracaibo en Venezuela, el cual habitaban desde épocas prehispánicas.

A principios de Siglo XX el pueblo Barí sufrió una intensa oleada de violencia conocida como el genocidio Barí, debido a la llegada de la Colombian Petroleum Company (COLPET) en 1930, luego de que la concesión Barco le arrendara los terrenos para la extracción de petróleo en

3 Anterior al proceso de reducción de su territorio, las comunidades del pueblo Barí eran seminómadas y se establecían por temporadas de cosecha y pesca en bohíos (ka) construidos alrededor de los ríos. 
lo que ahora es el municipio de Tibú. Esta consistió en el proceso sistemático de exterminio físico y cultural (Jaulin, 1973) y en la limitación de su territorio, razón por la que actualmente se encuentran ubicados en dos resguardos en la parte norte del Catatumbo, los cuales anteriormente fue el aréa de confinamiento por los procesos de violencia y colonización. A partir de estos sucesos se redujo drásticamente el territorio del pueblo Barí, y se introdujeron procesos de colonización que incrementaron su reducción, provocaron la desapareción de algunos de los bohíos y el confinamiento en las estribaciones de la serranía de los Motilones (Jaramillo, 1993, p. 249).

Para analizar la agudización del conflicto territorial y la agencia de cada uno de los actores presentes en el territorio, es importante comprender al Estado, como actor que ha sido explorado desde la antropología y la Ecología Política, en la configuración de los conflictos territoriales. Sin embargo, desde la geografía crítica ha sido considerado como un sujeto que define un territorio y que expresa estrategias regionales y locales (Schneider y Peyré Tartaruga, 2006). Su intervención en muchos casos ha generado impactos en las comunidades o ha incidido en los conflictos territoriales. Para el caso particular del pueblo Barí y su genocidio, el Estado coadyuvó al exterminio de varios miembros de la comunidad a través de la Ley 80 de $1931^{4}$, en el marco de la Concesión Barco, la cual permitía la contención por medio de la violencia hacia miembros de la comunidad Barí que se opusieran al proyecto petrolero. Este suceso, como la construcción de infraestructura para la extracción de petróleo y la ola de colonización de personas foráneas que posteriormente dio lugar a algunos municipios como Tibú, contribuyó a la imposición

4 La Ley 80 de 1931, por la cual se aprobó un contrato de explotación de petroleo en los yacimientos del Norte de Santander, donde en su numeral XIX expone lo siguiente: "El Gobierno les prestará a las Compañías contratantes la protección debida para prevenir o repeler la hostilidad o los ataques de las tribus de motilones o salvajes que moran en las regiones de que hacen parte los terrenos materia de este contrato, lo que hará por medio de cuerpos de policía armada o de la fuerza pública en cuanto sea necesario”. Además de poner otras disposiciones en materia de disponibilidad, uso y acceso al territorio y sus bienes por parte de la empresa. 
de una territorialidad y, por ende, a parte de la reducción del territorio Barí, así como la configuración de transformaciones territoriales en la región (CNMH, 2018, p. 43).

Por otro lado, el conflicto armado también propició varias transformaciones territoriales y la llegada de los grupos guerrilleros, quienes incidieron en la territorialidad de las comunidades campesinas e indígenas; posteriormente, en 1990, la llegada de grupos paramilitares impuso de forma violenta otras territorialidades, como sucedió con los proyectos agroindustriales en Tibú (CNMH, 2018). Es importante comprender que el conflicto armado en el Catatumbo configuró una geografía de poder, donde la violencia acentuó las desigualdades socioambientales y territoriales vinculadas a estos procesos, no solo contribuyó a vacios de poder por parte de la institucionalidad del Estado, sino que generó otras dinámicas de legalidad y legitimidad. Además, contribuyó a configurar geografías de acaparamiento y de consumo de la naturaleza (Ulloa y Coronado, 2016), así como lugares de resistencia.

\section{¿Implementación del Acuerdo de Paz y posconflicto en el Catatumbo?}

La firma del Acuerdo de Paz generó un sinnúmero de expectativas frente a la construcción de paz en el Catatumbo, especialmente en los ocho municipios que se priorizaron para la implementación de varios programas especificados en él, como los Programas de Desarrollo con Enfoque Territorial (PDET) ${ }^{5}$ o el Plan Nacional Integral de Sustitución de Cultivos

5 El punto 1 del Acuerdo de Paz: Reforma Rural Integral se construyó a partir de la identificación de las necesidades insatisfechas de la población rural en Colombia y de las condiciones estructurales que aumentaban la desigualdad entre el campo y la ciudad. Por lo tanto, los programas de este primer punto se enfocaron en ocho pilares que configurarán tanto la formulación del PDET como de los Planes Nacionales de Reforma Rural Integral y que permitirán dicho cambio estructural: ordenamiento social de la propiedad rural; infraestructura y adecuación de tierras; salud rural; educación rural; vivienda y agua potable; generación económica; derecho a la alimentación y seguridad alimentaria; y reconciliación, convivencia y paz. 
de Uso Ilícito (PNIS). Inicialmente se priorizaron 170 municipios con los siguientes criterios establecidos en el numeral 1.2. del Acuerdo de Paz:

- Los niveles de pobreza, en particular de pobreza extrema y de necesidades básicas insatisfechas;

- $\quad$ El grado de afectación derivado del conflicto;

- La debilidad de la institucionalidad administrativa y de la capacidad de gestión;

- La presencia de cultivos de uso ilícito y otras economías ilegítimas.

La Reforma Rural Integral (RRI) busca la caracterización eficiente de la situación agraria del país por medio de mecanismos como el catastro multipropósito, el Registro de Sujetos de Ordenamiento (RESO), así como mecanismos para hacer eficiente un régimen de titularidad de la propiedad o de tenencia de la tierra como se propone con el Decreto 902 de 2017 "por el cual se adoptan medidas para facilitar la implementación de la Reforma Rural Integral...” y el fortalecimiento de la estructura sociopolítica en todos los niveles territoriales. También se proponen en el Acuerdo de Paz mecanismos para "mejorar las condiciones de vida en la ruralidad y estrechar la brecha entre el campo y la ciudad a través de la garantía de derechos sociales a las comunidades rurales de Colombia” (Acuerdo final para la Paz, 2016; 7).

Esta coyuntura produjo una gran expectativa y escenarios de participación, y con ello lugares comunes para fomentar el diálogo con el fin de proponer soluciones a las condiciones de desigualdad y a los conflictos de vieja data instalados en el territorio, causados por la presencia diferenciada del Estado, las desigualdades territoriales, la extracción de recursos naturales y la violencia política contra las comunidades campesinas e indígenas. Igualmente, el Acuerdo de Paz concluye que para generar estos procesos de transformación es importante fortalecer la 
institucionalidad y garantizar los derechos básicos de las comunidades que habitan la región.

Otro elemento del posconflicto es que las propuestas alrededor de la implementación de los puntos del Acuerdo de Paz generaron la creación de varias entidades que tienen como objetivo la implementación de la RRI, como la Agencia Nacional de Tierras (ANT), la Agencia de Desarrollo Rural (ADR), Agencia de Renovación del Territorio (ART) y la Dirección de Sustitución de Cultivos de uso Ilícito (DSCI). Esta reformulación institucional tiene como propósito dar cumplimiento a cabalidad a las exigencias de las comunidades frente al Acuerdo de Paz, entendiendo que este busca solventar las causas del conflicto armado en el país, entre las cuales se identificaba el acceso a la tierra y su formalización, como afirmó la Comisión Histórica del Conflicto y sus Victimas (2015).

Sin embargo, el posconflicto generó otros escenarios y nuevas configuraciones de la geografía del poder. Con la desmovilización de las Fuerzas Armadas Revolucionarias de Colombia-Ejército del Pueblo (FARC-EP) y el cese de hostilidades por parte de este grupo, comenzó un escalamiento de acciones armadas por parte de otros grupos armados que ejercen presencia en el territorio, como lo evidencia el CNMH:

Después de que en 2016 dejara de operar el Frente 33 de las FARC, entre el ELN y el EPL se inició una confrontación militar por el control de la economía de la coca y otras rentas ilegales y por la expansión del EPL hacia Venezuela, en el Catatumbo bajo, y a zonas con presencia histórica del ELN. A estas disputas se sumaron diferencias políticas, como las mismas guerrillas han manifestado, en especial vinculadas con el tipo de acciones que ejercen y con la forma en que se relacionan con la población civil. Esta confrontación ha afectado en su conjunto a los habitantes del Catatumbo, incluyendo al pueblo Barí. (2018, p. 628).

A su vez, este escalamiento y configuración de nuevas oleadas de violencia, tanto como la falta de acceso a los programas de RRI y la lenta 
implementación del Acuerdo, ha contribuido al aumento de cultivos de uso ilícito en la región, que según el informe de la Oficina de las Naciones Unidas contra la Droga y el Delito (United Nations Office on Drugs and Crime-UNODC), para el 2018 y 2019 la región del Catatumbo, especialmente el municipio de Tibú, sigue siendo el segundo municipio con más presencia de cultivos de uso ilícito luego de Tumaco (UNODC, 2019). El mapa 1 muestra la densidad de cultivos aproximados en la región.

La expansión y concentración de estos cultivos en la zona del Catatumbo ha generado intereses por parte de grupos ilegales que libran una disputa armada por su control y las demás actividades de la cadena productiva. Además, para pensar el posconflicto en el Catatumbo es imprescindible una propuesta de desarrollo rural que esté articulada con la sustitución de los cultivos de uso ilícito y el problema de las drogas ilícitas. También han llegado al territorio otros actores como empresas agroindustriales de palma y empresas petroleras como la Iberoamericana Company, ambas con pretensiones en la zona de La Gabarra, Tibú. 


\section{Mapa 1. Ubicación de cultivos de uso ilícito - 2016}

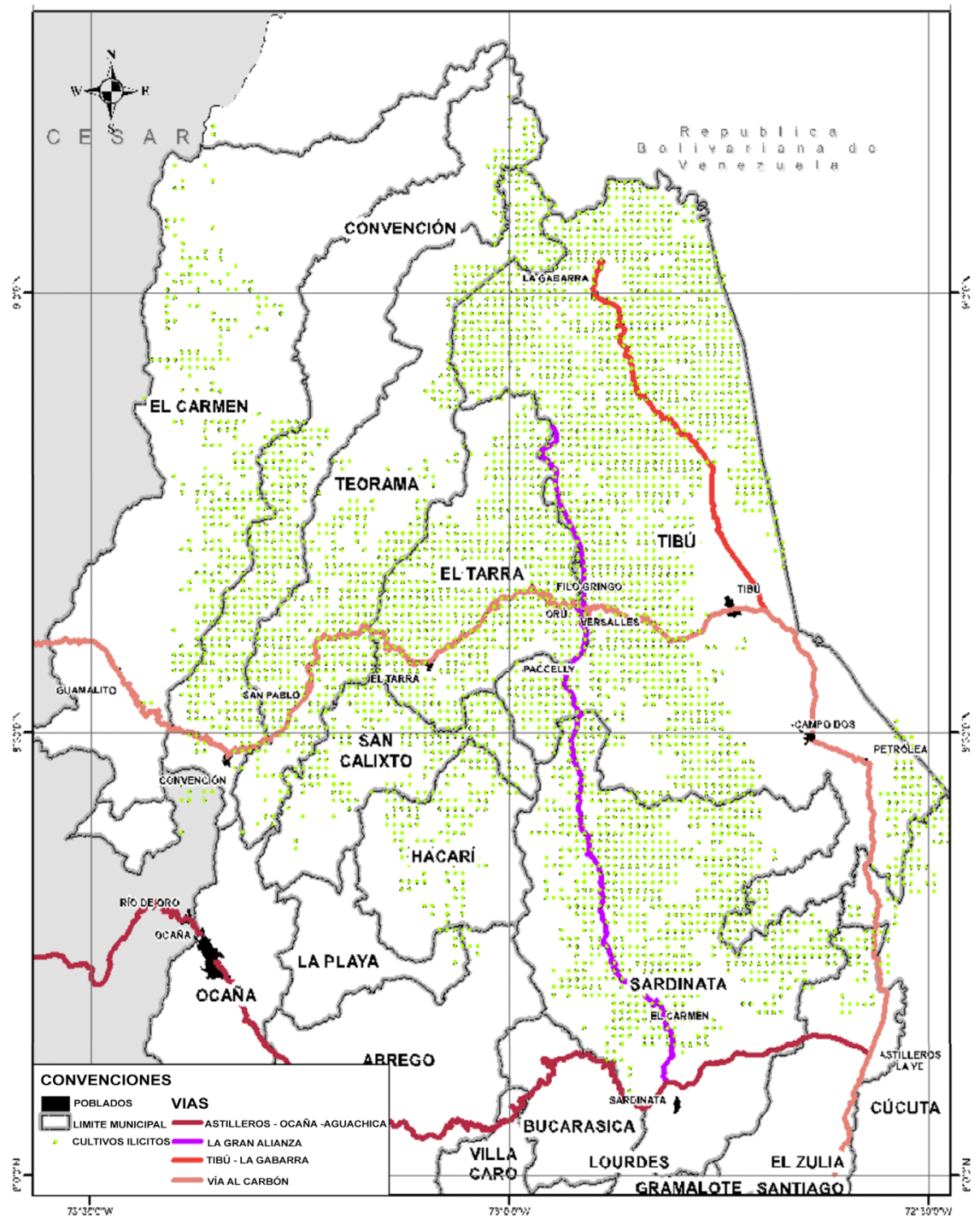

Fuente: SIMCI, UNODC (2016). Elaboración: Agencia Nacional de Tierras - Unidad de Gestión Territorio Norte de Santander (2018). 


\section{Conflictos territoriales y tensiones interétnicas en el marco del posconflicto}

Las comunidades y las organizaciones campesinas, especialmente AsCAMCAT, han participado en la implementación de los instrumentos propuestos en el Acuerdo de Paz como los PDET y el PNIS, buscando solventar las situaciones de desigualdad y exigir la garantía a sus derechos fundamentales. Con respecto a la RRI, los PDET evidenciaron las propuestas de ordenamiento de las comunidades, como la ampliación del resguardo, la constitución de la Zona de Reserva Campesina (ZRC) y la inclusión de los territorios campesinos agroalimentarios. Cabe anotar que estas dos últimas propuestas no quedaron en el Plan de Acción para la Transformación Regional (PATR), la ZRC sí para efectos de adelantar procedimientos de caracterización en el marco de la T-052 de 2017.

Dentro de sus mecanismos, la RRI exige elaborar una metodología para el trámite de conflictos territoriales e interétnicos, caso que en el Catatumbo no se cumplió, pues han sido las mismas comunidades y organizaciones las que han gestionado espacios para el diálogo y la resolución de conflictos, como ha sucedido con el pueblo Barí y algunas comunidades campesinas aledañas a ambos resguardos. Es claro que el lento avance de la implementación de este punto ha generado que muchos de estos instrumentos no se hayan desarrollado o no hayan funcionado propiamente, debido a la ausencia de otros instrumentos. Por ejemplo, para una efectiva implementación de las iniciativas del PDET era necesaria la ejecución de los Planes de Ordenamiento Social de la Propiedad Rural (POSPR), o la formalización de los planes nacionales para flexibilizar la implementación de las iniciativas en la ruralidad. A partir de esto podemos comprender la integralidad del Acuerdo de Paz, pues como se deduce el éxito de cada uno de los puntos está relacionado con el desarrollo de otro u otros. Además el PDET tenía un rol importante para el Punto 1, pues era la herramienta que materializaba las propuestas de diferentes dimensiones de lo que se comprendía como desarrollo rural. 
Sin embargo, la falta de articulación entre las instituciones del Gobierno Nacional responsables de hacer efectivos los puntos de la RRI, como la ART y la ANT, entre otras, provocó que en los escenarios de formulación de iniciativas de los espacios veredales y municipales del PDET o el PNIS, ${ }^{6}$ se evidenciara no solo la falta de articulación interinstitucional, sino la inexistencia de una ruta que brindara una solución integral a las peticiones de las comunidades y la falta de acompañamiento adecuado por parte de estas. Esto sumado a la desconfianza que existe debido a incumplimientos anteriores. Cabe anotar que debido a la falta de articulación nunca se lograron consolidar los Planes Integrales de Sustitución y Desarrollo Alternativo (PISDA) para la región, a pesar de la multiplicación de escenarios de participación que estos motivaron. Además, fue en estos escenarios donde las las tensiones que existían desde antes se manifestaron en intereses contrapuestos por parte de las comunidades participantes, como el traslape entre las pretensiones territoriales del pueblo Barí y ASCAMCAT. Otros aspectos que podrían generar más conflictos locales, como la entrada de otros actores en el territorio, por ejemplo, las empresas mineras de carbón o petroleras.

En muchas ocasiones el trámite no asertivo de estos conflictos generó la falta de articulación entre iniciativas campesinas e indígenas o que las tensiones en el territorio se intensificaran ${ }^{7}$, como sucedió con las obras de pequeña infraestructura comunitaria (PIC), ahora obras PDET. Además, el PATR, nunca tomó en cuenta el desarrollo de la Sentencia T-052 de 2017 con respecto a las Mesas de Territorio (pueblo Barí) o la

6 El Decreto Ley 896 de 2017 dio vía libre al PNIS, el cual hace parte de uno de los programas del punto 4 del Acuerdo de Paz: Solución al problema de las drogas ilícitas. Cabe anotar que la región del Catatumbo fue priorizada para la implementación del PNIS, debido a su alto número de cultivos. Sin embargo, solo logró dos acuerdos voluntarios de sustitución en los municipios de la región: Tibú y Sardinata.

7 Es importante señalar que durante el 2018 se presentaron varias manifestaciones de hecho de este conflicto, como el que sucedió en Saphadana - La Cooperativa, en el municipio de Convención. Donde el conflicto y los arreglos internos entre comunidades indígenas y campesinas provocó el desplazamiento de comunidades hacia Caño Tomas (Teorama). 
Mesa Consultiva, para articular las iniciativas regionales o dialogar entre los actores. Teniendo en cuenta que la Sentencia fue previa al inicio de la formulación del PDET.

Respecto al PNIS tampoco se dio un diálogo con el pueblo Barí de cara a una propuesta de sustitución con enfoque étnico y para la salvaguarda del territorio, a pesar de que hay presencia de cultivos en el territorio. Con base en estos casos es que se plantea la acción del Estado como generadora de conflictos, pues fue la inoperancia de sus instituciones y programas la que incentivó muchas tensiones entre campesinos e indígenas, bien por falta de información, bien por falta de acompañamiento o por el cumplimiento de lo dispuesto en la Sentencia T-052 de 2017. Actualmente, el Gobierno Nacional está llevando a cabo la implementación de una Ruta Futuro, que propone la forma de implementación de un PATR para el Catatumbo el cual se materializa en los planes de desarrollo. Cabe aclarar que todo lo anterior, se da en tiempos institucionales, otra de las grandes discordias entre la comunidad y el Estado.

No obstante, a pesar de que estos nuevos escenarios motivan a visibilizar una pluralidad de voces y visiones que resaltan las propuestas territoriales de las comunidades campesinas e indígenas del Catatumbo como elementos para la construcción de una geografía crítica en Colombia y como propuestas para un desarrollo alternativo, estas no han sido tomadas en cuenta y, al contrario, han incrementado las conflictividades en la región. Para ilustrar esta situación se retoma la tensión existente entre la formalización y delimitación de la zona de Reserva Campesina del Catatumbo (ZRCCA) y las pretensiones de ampliación, delimitación y saneamiento de los dos resguardos del pueblo Barí. Desde la perspectiva jurídica y política, esta tensión de territorialidades se expresa en un conflicto por la constitución y formalización de dos figuras de ordenamiento territorial existentes o de dos proyectos de territorialidades. Con respecto a la ZRCCA, su formulación empezó desde el 2014 en los municipios de Tibú, El Tarra, Teorama, Convención, El Carmen, San Calixto y Hacarí. A partir de estos ejercicios de socializa- 
ción e identificación de problemáticas del campesinado, con la ayuda técnica del Instituto Colombiano de Desarrollo Rural (INCODER), en el 2015 se consolidó el Plan de Desarrollo Sostenible el cual es el documento base para la formalización de la ZRC.

Por otro lado, el pueblo Barí también estuvo adelantando el proceso de ampliación de ambos resguardos con el INCODER al ver que las pretensiones de la ZRCCA se traslapaban con las suyas, e interpuso una tutela el 19 de marzo de 2014 a nombre de Diego Dora como integrante de NatubaiyiBarí. En mayo de 2017 la Corte Constitucional, mediante la Sentencia T-052, falló a favor del pueblo Barí y ordenó: a la ANT realizar una serie de acciones preparatorias para concluir con el trámite de ampliación, saneamiento y delimitación de resguardos; al Ministerio del Interior adelantar, en caso de ser necesario, consulta previa respecto a la solicitud de constitución de la ZRCCA; y la creación de una Mesa Consultiva entre la comunidad indígena Barí y las comunidades campesinas representadas en ASCAMCAT, para adelantar la elaboración de medidas de desarrollo alternativo en lugares donde convergen comunidades campesinas e indígenas.

Lo que se puede analizar del desarrollo de esta tensión entre propuestas territoriales expresadas en una forma de ordenamiento territorial propia, es que el Estado ha sido un actor fundamental en la agudización o escalamiento de los conflictos en el territorio. En el Catatumbo, como ha sucedido en otras regiones, la falta de control eficaz y el desconocimiento del territorio por parte del Estado han generado traslapes en las figuras de ordenamiento territorial o "cortos circuitos" entre las legislaciones agraria y ambiental, y lo que sucede en el territorio. Otro elemento, es que este proceso se dificulta al no haber un catastro actualizado, como se evidenció en discusiones sobre las pretensiones. Tampoco se han tenido en cuenta los territorios compartidos entre las comunidades y que están organizados a partir de un ejercicio autónomo, no fragmentado, lo que ha llevado a invisibilizar otro tipo territorialidades diversas. 
Comprender lo anterior es posible desde la Ecología Política y la geografía crítica, y más concretamente desde lo que Agnew y Oslender (2010) denominan territorialidades superpuestas. Según sus plantemientos, se retoma y analiza la existencia o coexistencia de varias territorialidades en un mismo espacio, y la territorialidad se concibe como una estrategia que se construye a partir de la producción de nociones del territorio que responde a la forma de habitar y producir el espacio de un actor específico. Este concepto ayuda a analizar y situar la existencia de otras formas de "fuentes de autoridad territorial" distintas a las del Estado-nación (Agnew y Oslender, 2010, p. 193). En ese sentido, la disputa por la permanencia en el territorio que libran las comunidades indígenas y campesinas también representa una lucha por el reconocimiento de su territorialidad y su autonomía, y en el caso del pueblo Barí debe entenderse

como el derecho a la integridad del territorio, a la ocupación y recuperación de áreas de asentamiento, a la circulación, a las actividades económicas, sociales y culturales que garanticen la pervivencia y el desarrollo (...) así como el derecho a la propiedad colectiva adquirido conforme a la Constitución y las Leyes. (ÑatubaiyiBarí, 2016).

Por otro lado, para las comunidades campesinas agrupadas en ASCAMCAT la territorialidad se define como un ejercicio de apropiación simbólica, material y ambiental en la construcción del campo; esto se realiza mediante la implementación de sistemas de economías campesinas en los territorios donde habitan las comunidades (Documento Acuerdo Mesa Consultiva, Mesa Consultiva, 2017).

Sobre definiciones construidas en el marco de las propuestas territoriales expresadas en pretensiones, en el mapa 2 la zona gris muestra el traslape entre la formalización de la ZRC y la solicitud de ampliación del pueblo Barí. El reconocimiento de territorialidades diversas ayuda a comprender el ejercicio de autonomía, con intencionalidades diferentes y proyectos políticos que se expresan en proyectos geográficos construidos desde diferentes lógicas territoriales. Por lo que, en este caso, la de- 
fensa de una propuesta de ordenamiento del territorio no solo expresa la pretensión sobre un pedazo de tierra, sino que implica la posibilidad de construir un proyecto territorial con intenciones distintas frente a lo que implica el desarrollo y la autonomía.

Por esa razón, para el caso del pueblo Barí y ASCAMCAT, en el marco del desarrollo de la Sentencia T-052 de 2017, ambas comunidades definieron lo que para ellas significa el desarrollo. Para el pueblo Barí, el desarrollo propio solo puede ser comprendido bajo el concepto del Buen Vivir, el cual se ha constituido en una oportunidad para construir colectivamente una alternativa al desarrollo y una relación armónica con la naturaleza. Así pues, el Buen Vivir para el pueblo Barí, desde su cosmovisión, no puede ser reducido al bienestar social vinculado al concepto de desarrollo, sino que significa la integralidad del territorio. El Plan de Vida del resguardo Motilón Barí describe el Buen Vivir como "el derecho de los pueblos a desarrollar políticas, programas y proyectos, que estén en armonía con nuestra cosmovisión, donde la ganancia economicista no es el eje fundamental, quitándole preeminencia al sentido devastador del desarrollo según la visión occidental” (ÑatubaiyiBarí, 2016; 11). El buen vivir es el equilibro con el isthana, el cual se ha venido perdiendo progresivamente con la reducción del territorio y la invasión de las tierras por parte de otros actores. 
Mapa 2. Traslapes entre pretensiones de ampliación de resguardos del pueblo Barí y la Zona de Reserva Campesina del Catatumbo

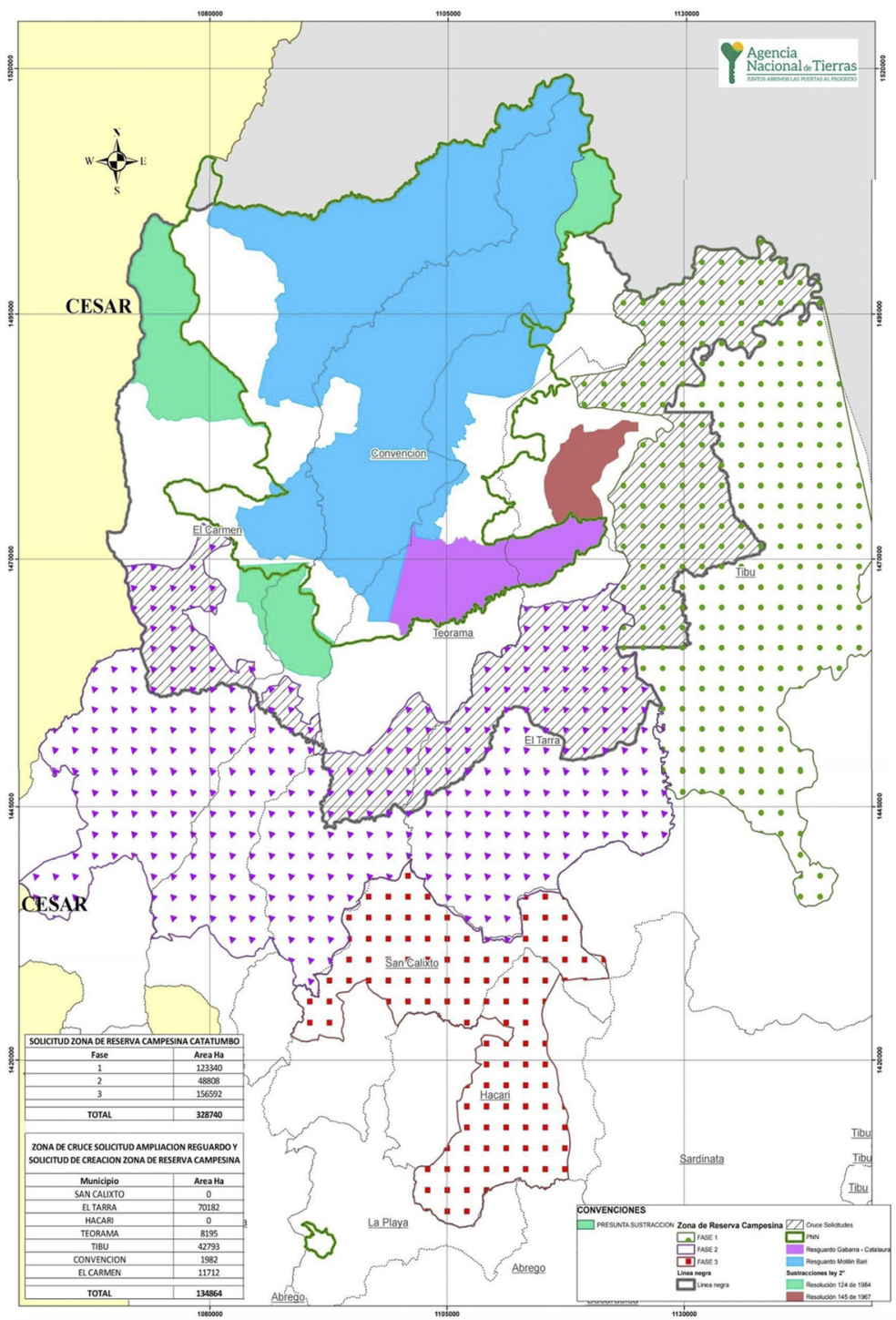

Fuente: Agencia Nacional de Tierras - Unidad de Gestión Territorio Norte de Santander (2018). 
Por su parte, las comunidades campesinas reconocen el desarrollo sostenible desde una visión alejada del extractivismo y explotación a gran escala, y como propuesta de desarrollo alternativo al desarrollo capitalista, que rescata la economía campesina y familiar como dinamizadora del territorio. En ese sentido proponen como principio fundamental para su modo de vida las formas de producción tradicionales del campesinado como cultivos de pequeña escala y garantías para la formalización, producción, comercialización y distribución de sus productos como propuesta de soberanía alimentaria. En el Plan de Desarrollo Sostenible presentado por ASCAMCAT se sostiene que el modelo de economía campesina

se presenta como una alternativa al desarrollo socioeconómico, agropecuario, cultural y político desde el cual se superen las políticas y programas asistencialistas, y se logre una alternativa de desarrollo integral para el campesinado y la sociedad en general. Proyectando la región del Catatumbo y su Zona de Reserva Campesina (ZRC-C) como un modelo en la producción de alimentos para la región, el departamento y el país, que permita la independencia y la soberanía alimentaria de sus pobladores (ASCAMCAT, 2012, p. 31).

Dicho modelo podría ser analizado a la luz del concepto políticas del lugar de Arturo Escobar, quien propone que sea "una forma emergente de política, un inusitado imaginario político en el cual se afirma una lógica de diferencia y posibilidad que construye sobre la multiplicidad de acciones en el plano de la vida cotidiana” (2010, p. 79). Estas políticas de defensa territorial posicionan el territorio como un lugar donde confluyen culturas, visiones de mundos, economías y ambientes dinámicos que proponen alternativas al desarrollo para la defensa del ambiente. Para este caso, se plantea construir una alternativa entre ambas comunidades desde lo ambiental, pues se concluyó que ese fue el primer punto de confluencia entre el pueblo Barí y las comunidades campesinas, en el marco de la Mesa Consultiva que ordenó la sentencia. Razón por la cual no aparecen otras propuestas de comunidades campesinas 
pertenecientes a otras organizaciones, como los territorios campesinos agroalimentarios del CISCA o las zonas forestales del MCP.

\section{Territorialidades indígenas y campesinas}

Las exigencias de las comunidades campesinas e indígenas frente a la formalización de la tierra pasan no solo por un reconocimiento del derecho al territorio, sino de la justicia social integral que propone Fraser y que se puede interpretar como "los reclamos desde la redistribución como desde el reconocimiento y, por lo tanto, ninguno de esos dos elementos es suficiente por sí mismo” (cit. por Montaño y Trejos, 2017, p. 23). Es decir, que tanto la ampliación del resguardo como la constitución de la Zona de Reserva Campesina del Catatumbo implican un reconocimiento de su territorialidad como campesinado frente a los demás, y especialmente como una forma de exigir sus derechos frente al Estado. Para Montaño y Trejos (2017) tanto las comunidades indígenas como las campesinas han construido su propia noción de justicia y es el territorio el lugar donde se materializan estas exigencias, pues para

el movimiento indígena, una visión integral de justicia se cristaliza en el territorio indígena, más allá de una simple delimitación territorial y en relación con los derechos diferenciados de orden constitucional que en su cabeza se reconocen. Asimismo sucede con el movimiento campesino, para el cual una visión integral de justicia se cristaliza, entre otras, por comprender las ZRC más allá de una delimitación territorial con base en una forma de percibir sus derechos (2017, p. 39).

Lo complejo del asunto es que es el territorio el espacio donde se materializan las exigencias de cada actor, así como el factor que representa más tensión entre las partes, pues el territorio implica el desarrollo de actividades que generan, por ejemplo, choques entre indígenas y campesinos, como ocurrió frente al uso del suelo para actividades de ganadería de búfalo o de cultivos de uso ilícito, o la restricción de movilidad para lugares sagrados. Razón para ahondar en los acuerdos cotidianos 
que ya existen entre las comunidades, quienes desde hace tiempo han construído sus proyectos territoriales, desde la resistencia y la protección del territorio. No obstante, es importante recordar el carácter del territorio donde ambos proyectos tienen distinta sintonía, a veces en aspectos como el uso del suelo o en la representación misma del territorio.

Si bien para ambas comunidades el territorio representa una integración entre el espacio, las relaciones sociales y la cultura, para los Barí es la vida misma pues gracias a este es que perviven en el Catatumbo. Salazar (2005, p. 6), en su informe final sobre el territorio tradicional del pueblo Barí, citando a Ramos señala: "para las sociedades indígenas, la tierra es mucho más que un medio de subsistencia. Ella representa el soporte de la vida social y está directamente ligada al sistema de creencias y conocimiento. No es sólo un recurso natural”. El reconocimiento de su territorio también les permite a los Barí un ejercicio de autonomía y autodeterminación, como el reconocimiento de la reducción que ha tenido su territorio ancestral.

En cambio, para las comunidades campesinas representadas en la Asociación Nacional de Zonas de Reserva Campesina (ANZORC) el territorio es una forma de reconocimiento a la economía campesina y a la necesidad de formalizar sus tierras, pues se trata de un

espacio de conciencia de derechos con identidad campesina, es decir, donde vivimos, donde trabajamos, cultivamos, convivimos, es nuestro sitio propio donde hay cultura, tierra, oro, agua, plantas, madera, alimentos; en otras palabras, es una interrelación de las dimensiones sociales, culturales, económicas y políticas de las comunidades. (2012, p. 34).

Otro elemento que distancia la noción de territorio entre ambas comunidades es la propiedad y el cuidado de la naturaleza misma. Por un lado, el pueblo Barí no comprende el concepto de propiedad impuesto por la sociedad occidental, donde cada quien adquiere sus pertenencias a través del dinero, pues para sus miembros la tierra es una propiedad 
colectiva ancestral, así como el territorio es la vida misma. No obstante, se ha integrado a la lucha por la ampliación, delimitación y saneamiento de su resguardo como una estrategia de defensa del territorio y sus lugares sagrados, dando otra vez un uso estratégico a las normas gubernamentales, aunque no coincidan con su visión del mundo. Esto se evidencia cuando señalan que quieren defender no solo la porción de tierra, sino también los lugares de producción de niebla, los lugares donde las aves llegan y donde los árboles esparcen sus semillas.

Para el caso de las comunidades campesinas, Montaño y Trejos (2017) afirman que el territorio pasa por las exigencias de reconocimiento de la tierra y de la economía campesina ignorada por el sistema económico (p. 23), toda vez que "el campesino, como sujeto político, no figura en el texto constitucional, pues tan solo hay mención que hace referencia al trabajador agrario” (38). Así, las diferencias en materia de exigencias territoriales entre los indígenas y campesinos se sostienen, en su gran mayoría, en argumentos de orden cultural como menciona Ulloa (2014), lo cual en ciertas ocasiones puede dificultar un diálogo interétnico. Sin embargo, aunque algunos mecanismos institucionales de resolución de conflictos ahondan en estas diferencias, es importante construir estrategias desde lo local que sintonicen puntos de confluencia como la importancia de reconocer el pensamiento de ambas partes.

Montaño y Trejos (2017) afirman que uno de los puntos que puede generar discordias o tensiones es el reconocimiento por parte del Estado de los derechos de las comunidades étnicas, mientras que las comunidades campesinas aún están luchando por avanzar en ese sentido (p. 24). A pesar de estas diferencias y dificultades, la Mesa Consultiva ha sido un espacio para la defensa del Catatumbo por parte de ambas comunidades, además, reconociendo que la Sentencia T-052 del 2017, acepta que existe una vulneración de derechos territoriales hacia ambas partes y que por eso, la Mesa se convierte en el escenario para formular medidas de "desarrollo alternativo". 
Continuando, empresas petroleras y palmicultoras, como sucede desde el 2018 ante la amenaza de concesión a la Iberoamericana de Petróleos en la zona de La Gabarra o de los títulos para minería de carbón, como lo socializó la Corporación Autónoma Regional de la Frontera Nororiental (CORPONOR), en febrero de 2019. Fernandes (2005) resalta la importancia de los movimientos socioterritoriales, debido a que estos comprenden el territorio como producto de las relaciones de poder, y en ese sentido el ejercicio de control territorial por parte de las comunidades es una forma de la defensa ambiental de la región, ante estas amenazas. Este elemento ha sido trascendental en la construcción de una defensa colectiva del Catatumbo. Ulloa y Coronado (2016) resaltan que estos procesos no solo expresan el sentido de justicia social, sino también de la justicia ambiental y la discusión sobre el lugar que ocupan en estos procesos la naturaleza y las resistencias de las comunidades con sus propuestas alternativas frente al territorio (p. 24). En virtud de lo anterior se puede concluir que lo ambiental ha logrado constituirse en un factor de diálogo y gestión de las desigualdades y conflictos desde las comunidades, en zonas que históricamente han sido afectadas por el conflicto armado o por intereses económicos de distintos actores.

\section{Conclusiones}

El posacuerdo generó escenarios de conflictividad, así como oportunidades para reconocer formas de encuentro y negociación entre comunidades con distintos intereses, atravesadas por condiciones estructurales diferentes como la historia y la cultura. En los escenarios donde el conflicto armado disminuyó por un momento, esto permitió el reconocimiento de modalidades de apropiación del territorio y sus recursos, la convergencia de prácticas e imaginarios colectivos y la visibilización de tensiones entre actores, como ocurre entre el pueblo Barí y ASCAMCAT.

A pesar de que el posacuerdo y para este caso, el posconflicto, brindan la posibilidad de generar varios escenarios de diálogo entre los actores de la región, por tratarse de conflictos estructurales de vieja data re- 
quieren de una comprensión particular de las necesidades y la noción que cada una de las partes tiene del territorio, de la apropiación de la naturaleza y de las territorialidades. Es importante mencionar la importancia de la apropiación de las herramientas que brinda el Acuerdo de Paz, para el reconocimiento de territorialidades excluídas históricamente, así para no ahondar en el escalamiento de la violencia en otros escenarios, incluso el armado.

El Estado, como actor que hace presencia en el territorio, se ha quedado corto no solo en su intervención, sino en los mecanismos de resolución de conflictos y en materia de coordinación interinstitucional. Ante la complejidad de la situación del Catatumbo, corresponde al Estado comprender que la lucha por el territorio, representada en una propuesta de ordenamiento territorial, no se reduce a la posesión de un pedazo de terreno, sino que debe incluir la concepción que al respecto tiene cada una de las partes involucradas, pues mientras para el pueblo Barí este representa la vida misma desde la autonomía y el gobierno propio, para los campesinos conlleva la materialización de sus derechos. En ese sentido, el acceso a la tierra representa el reconocimiento de la territorialidad ante el Estado y lo que ello entraña: atención no solo a los reclamos de redistribución, sino a los llamamientos de justicia social, expresada en el acceso a derechos fundamentales y servicios básicos, que a su vez contribuye a una concepción de justicia espacial de las comunidades campesinas e indígenas.

La sentencia T-052 de 2017 contribuyó a visibilizar el conflicto por el territorio y formuló un llamado a las instituciones del Gobierno Nacional para atenderlo. Por otro lado, las comunidades indígenas lograron visibilizar y posicionar sus propuestas de resistencia y defensa de derechos territoriales, y las comunidades campesinas pudieron expresar reclamos y exigencias derivados del hecho de haber sido invisibilizadas históricamente. Además, esta sentencia contribuyó en el reconocimiento del derecho a la ancestralidad de las comunidades Barí, cuando señala con el procedimiento de ampliación busca una forma de revertir 
el despojo perpetuado hacia esa comunidad, reconociendo que ya existían sentencias a su favor como la T-880 de 2006. Igualmente y como se mencionó antes, que esta sentencia reconoce que hay vulneración de derecho hacia ambas partes y que se debe solucionar las cuestiones relacionadas con las pretensiones.

No obstante, el reconocimiento de los reclamos y derechos de las dos partes abre una ventana de oportunidades en que la disputa del territorio se puede complejizar por involucrar nuevos actores con nuevos intereses, teniendo en cuenta la reconfiguración actual del conflicto armado en el Catatumbo. Aún así, es una oportunidad para analizar desde la ecología política los conflictos territoriales y las desigualdades estructurales (Göbel y Ulloa, 2014). Por esa razón es importante adelantar la implementación de la Sentencia de manera participativa y consensuada. Al igual que el Acuerdo de Paz en cada uno de sus mecanismos, los cuales contribuyen a la construcción de paz territorial, reconociendo las territorialidades diversas que se presentan en el territorio con sus proyectos geográficos respectivos. Todo esto para comprender que las comunidades han construído propuestas de paz desde el territorio y estas deben ser tenidas en cuenta para evitar nuevos escalamientos de violencia. 


\section{Referencias}

Agnew, John y Oslender, Ulrich. (2010). Territorialidades superpuestas soberanía en disputa: lecciones empíricas desde América Latina. Tabula Rasa (13), 191-213.

Asociación Campesina del Catatumbo [ASCAMCAT]. (2012). Plan de desarrollo sostenible. Cúcuta: Instituto Colombiano de Desarrollo Rural.

Asociación Nacional de Zonas de Reserva Campesina. (2011). Cartilla pedagógica de las zonas de reserva campesina en Colombia. Obtenido de issuu: https://issuu.com/ANZORC/docs/cartillazonasdereservacampesina

Centro Nacional de Memoria Histórica. (2018). Catatumbo. Memorias de vida y dignidad. Bogotá: Centro Nacional de Memoria Histórica/Diócesis de Tibú/Programa de Apoyo a la Construcción de la Paz en Colombia

Comisión Histórica del Conflicto y sus Víctimas. (2015). Contribución al entendimiento del conflicto armado en Colombia. Bogotá: Ediciones Desde Abajo.

Escobar, A. (2010) Territorios de diferencia. Lugar, movimientos, vida, redes. Evión Editores.

Fernandes Mançano, Bernardo. (2005). Movimientos socioterritoriales y movimientos socioespaciales. Obtenido de web.ua: https://web.ua.es/en/giecryal/documentos/documentos839/docs/bmfunesp-5.pdf

Guevara Agudelo, Laura María. (2017). El caso del Catatumbo y los desencuentros por el reconocimiento de derechos territoriales. En Cindy Duarte y Michael Cruz (Coords.), Paz en el territorio. Diálogo intercultural y justicia social (pp. 118-136). Bogotá: Universidad Nacional de Colombia.

Göbel, Barbara y Ulloa, Astrid. (2014). Colombia y el extractivismo en América Latina. En Barbara Göbel y Astrid Ulloa (Eds.), Extractivismo minero en Colombia y en América Latina (pp. 15-33). Bogotá: Universidad Nacional de Colombia/Ibero- Amerikanisches Institut.

Jaramillo, Orlando. (1993). Los Barí. En Geografía Humana de Colombia Nordeste Indígena (t. II). Bogotá: Instituto Colombiano de Cultura Hispánica.

Jaulin, Robert. (1973). La paz blanca: introducción al etnocidio. Buenos Aires: Tiempo Contemporáneo. 
Montaño Jennifer y Trejos, Carolina. (2017). Movimiento indígena y movimiento campesino. Luchas por la justicia social. En Cindy Duarte y Michael Cruz (Coords.), Paz en el territorio. Diálogo intercultural y justicia social (pp. 19-74). Bogotá: Universidad Nacional de Colombia.

NatubaiyiBarí. Asociación de Autoridades Tradicionales del Pueblo Barí. (2016). Plan de Vida InchidjiChibidondomain. Tibú: Autor.

Salazar, Carlos Augusto. (2005). Ishtana, el territorio tradicional Barí. Informe final sobre territorio tradicional del pueblo indígena Barí, región del Catatumbo, Norte de Santander. Ocaña: Asociación de Autoridades Barí/Centro de Cooperación al Indígena/ Oxford Committee for Famine Relief.

Sergio Schneider e Iván G. Peyré Tartaruga (2006). Territorio y enfoque territorial: de las referencias cognitivas a los aportes aplicados al análisis de los procesos sociales rurales. En: Manzanal, Mabel; Neiman, Guillermo y Lattuada, Mario. (Org.). Desarrollo Rural. Organizaciones, Instituciones y Territorio. (pp. 71-102). Buenos Aires: Ed. Ciccus.

Ulloa, Astrid. (2014). Geopolíticas del desarrollo y la confrontación extractivista minera: elementos para el análisis de territorios indígenas. En Barbara Göbel y Astrid Ulloa (Eds.), Extractivismo minero en Colombia y América Latina (pp. 425-458). Bogotá: Universidad Nacional de Colombia/Iberoamerikanisches Institut.

Ulloa, Astrid y Coronado, Sergio. (2016). Territorios, Estado, actores sociales, derechos y conflictos socioambientales en contextos extractivistas: aportes para el posacuerdo. En Astrid Ulloa y Sergio Coronado (Eds.), Extractivismos y posconflicto en Colombia: retos para la paz territorial (pp. 2358). Bogotá: Universidad Nacional de Colombia/ Centro de Investigación y Educación Popular.

Zaragocin, Sofía; Moreano, Melissa y Álvarez, Soledad. (2018). Hacia una reapropiación de la geografía crítica en América Latina. Presentación del dossier. Íconos, (61), 11-32. 


\section{Documentos consultados}

Gobierno Nacional y Farc-Ep. (2016). Acuerdo final para la terminación del conflicto y la construcción de una paz estable y duradera. La Habana, Cuba: Autores.

Asociación Comunidades Indígenas Motilón Barí de Colombia (AsocBARí). (2004). Plan de vida: Ichidji ya ababi. Algo nuestro, así somos los Barí. Tibú.

Documento Acuerdo Mesa Consultiva - Medidas para la protección ambiental de las zonas de traslape, identificadas a partir de las pretensiones territoriales del Pueblo Barí y la comunidad campesina representada en ASCAMCAT. (Noviembre de 2018).

Instituto Kroc de Estudios Internacionales de Paz (Agosto 2018). Segundo informe sobre el estado efectivo de implementación del Acuerdo de Paz en Colombia (diciembre 2016-mayo2018). Escuela Keough de Asuntos Globales. Universidad de Notre Dame.

Oficina de las Naciones Unidas Contra la Droga y el Delito [UNODC]. (Agosto de 2019). Monitoreo de territorios afectados por cultivos ilícitos 2018. Bogotá: Oficina de las Naciones Unidas Contra la Droga y el Delito/Sistema Integrado de Monitoreo de Cultivos Ilícitos. 